\title{
Impaired Functions of Peripheral Blood Monocyte Subpopulations in Aged Humans
}

\author{
Joseph Nyugen • Sudhanshu Agrawal • \\ Sastry Gollapudi • Sudhir Gupta
}

Received: 30 June 2010 / Accepted: 22 July 2010 /Published online: 12 August 2010

(C) The Author(s) 2010. This article is published with open access at Springerlink.com

\begin{abstract}
Aging is associated with increased susceptibility to microbial infections, and monocytes play an important role in microbial defense. In this study, we have identified and compared four subpopulations of monocytes $\left(\mathrm{CD} 14^{++(\text {(high) }}\right.$ $\mathrm{CD} 16^{-}, \mathrm{CD} 14^{+(\text {low })} \mathrm{CD} 16^{-}, \mathrm{CD} 14^{++(\text {high })} \mathrm{CD} 16^{+}$, and $\left.\mathrm{CD} 14^{+(\text {low) }} \mathrm{CD} 16^{+}\right)$in the peripheral blood of young and aged subjects with regard to their numbers, cytokine production, TLR expression, and phosphorylation of ERK1/2 in response to pam3Cys a TLR-1/2 ligand. Proportions and numbers of $\mathrm{CD} 14^{++(\text {high) }} \mathrm{CD} 16^{+}$and $\mathrm{CD} 14^{+ \text {(low) }} \mathrm{CD} 16^{+}$monocytes were significantly increased, whereas proportions of $\mathrm{CD} 14^{+ \text {(low) }}$ CD16 monocytes were decreased in aged subjects as compared to young subjects. In aged subjects, IL-6 production by all four subsets of monocytes was significantly decreased, whereas TNF- $\alpha$ production was decreased in monocyte subsets, except the $\mathrm{CD} 14^{+(\text {low })} \mathrm{CD} 16^{-}$subset. A significantly reduced expression of TLR1 was observed in $\mathrm{CD} 14^{++ \text {(high) }}$ $\mathrm{CD} 16^{+}$and $\mathrm{CD} 14^{+(\text {low })} \mathrm{CD} 16^{+}$monocyte subsets in aged subjects. Furthermore, following pam3Cys stimulation, ERK1/2 phosphorylation was significantly lower in $\mathrm{CD} 14^{+(\text {low })} \mathrm{CD} 16^{+}, \mathrm{CD} 14^{++(\text {high })} \mathrm{CD} 16^{+}$, and $\mathrm{CD} 14^{+(\text {low })}$ CD16 subsets of monocytes from aged subjects. This is the first study of four subpopulations of monocytes in aging, which demonstrates that their functions are differentially impaired with regard to the production of cytokines, expression of TLR, and signaling via the ERK-MAPK pathway. Finally, changes in the number of monocyte subsets, and impairment of TLR1 expression, TNF- $\alpha$ production, and EK1/2 phosphorylation was more consistent in $\mathrm{CD}_{16}{ }^{+}$
\end{abstract}

\footnotetext{
J. Nyugen $\cdot$ S. Agrawal $\cdot$ S. Gollapudi $\cdot$ S. Gupta $(\bowtie)$

Division of Basic and Clinical Immunology,

University of California,

Med. Sci. I, C-240,

Irvine, CA 92697, USA

e-mail: sgupta@uci.edu
}

monocyte subsets regardless of expression of $\mathrm{CD} 14^{\text {high }}$ or $\mathrm{CD} 14^{\text {+low }}$, therefore highlighting the significance of further subdivision of monocytes into four subpopulations.

Keywords TLR $\cdot$ monocyte subsets $\cdot$ cytokines $\cdot$ signaling

\section{Introduction}

Aging is associated with a progressive immune deficiency rendering aged subjects susceptible to infections and displays impaired response to vaccination [1-3]. Monocytes play an important role in defense against microbial pathogens and inflammation $[4,5]$. Heterogeneity of monocytes is now well established. Two distinct subpopulations of monocytes $\left(\mathrm{CD} 14^{++(\text {high })} \mathrm{CD} 16^{-}\right.$and $\left.\mathrm{CD} 14^{+(\text {low })} \mathrm{CD} 16^{+}\right)$were described by Passlick et al. [6]. These two subsets of monocytes are distinct with regard to certain cell surface molecules, migration properties, and their functions [7-12]. $\mathrm{CD} 14^{++(\text {high) }} \mathrm{CD} 16^{-}$subpopulation of monocytes expresses CD62L, CD64, and CCR2 with low levels of CXCR1 [12]. In contrast, $\mathrm{CD} 14^{+(\text {low })} \mathrm{CD} 16^{+}$ monocytes lack CD62L, CD64, or CCR2 but express high levels of CX3CR1. CD14+CD16+ monocytes are considered pro-inflammatory monocytes since they produce increased levels of TNF- $\alpha$ and low levels of antiinflammatory IL-10 in response to Toll-like receptors (TLR2 and TLR-4 agonists [12-14]. Renshaw et al. [15] reported decreased expression of all TLRs in both splenic and activated peritoneal macrophages from aged mice as compared to young mice. Furthermore, they demonstrated that macrophages from aged mice secreted significantly less IL- 6 and TNF- $\alpha$ upon stimulation with TLR ligands.

In the present study, we report for the first time numerical and functional analyses of four subpopulations of peripheral 
blood monocytes $\left(\mathrm{CD} 14^{++(\text {(high) }} \mathrm{CD} 16^{-}, \mathrm{CD} 14^{+ \text {(low) }} \mathrm{CD} 16^{-}\right.$, $\mathrm{CD} 14^{++(\text {high) }} \mathrm{CD} 16^{+}$, and $\mathrm{CD} 14^{+(\text {low })} \mathrm{CD} 16^{+}$) in young and aged humans, and demonstrate a functional defect in TLR1/ 2 -induced IL- 6 and TNF- $\alpha$ production in aged subjects, which appears to be associated with decreased expression of TLR1 and is likely mediated via impaired ERK-MAPK signaling pathway.

\section{Materials and Methods}

Peripheral blood from 17 young (age 21-32 years) and 17 aged (age 66-89 years) subjects was used for the present study. These subjects are of middle-class social status, and aged subjects are living independent, healthy lives, and they were asked to stop taking all anti-oxidants (which many aged subjects take on a regular basis) for at least 1 week prior to obtaining blood samples to avoid their effects on the present investigation. The study is approved by Institutional Review Board (Human) of the University of California, Irvine.

Determination of Monocyte Subsets and the Expression of TLR 1 and TLR2

Expression of TLR1 and TLR2 on monocyte subsets was determined by flow cytometry using FITC- conjugated antiCD14, Alexa Fluor 647-labeled anti-CD16 antibodies (BD Biosciences, San Diego, CA, USA) and PE-labeled antiTLR2 antibodies (e-Biosciences, San Diego, CA, USA). Briefly, $100 \mu \mathrm{l}$ of whole blood was incubated with $10 \mu \mathrm{l}$ of each of the anti-CD14, anti-CD16, and anti-TLR1 or antiTLR2, or isotype control antibodies for $15 \mathrm{~min}$ at room temperature in the dark. Cells were then incubated in $2 \mathrm{ml}$ of FACS lysing solution (Becton-Dickinson, San Jose, CA, USA) for $15 \mathrm{~min}$ to lyse red blood cells and washed twice with phosphate-buffered saline $(1 \times$ PBS $)$, and the cells were resuspended in $0.5 \mathrm{~mL}$ of $1 \%$ paraformaldehyde and analyzed by FACSCalibur.

\section{Measurements of Intracellular IL-6 and TNF- $\alpha$}

Whole peripheral blood was activated with $5 \mu \mathrm{g} / \mathrm{ml}$ of TLR1/TLR2 ligand pam3cys (Invivogen, San Diego, CA, USA) in the presence of Brefeldin A for $4 \mathrm{~h}$. After CD14/ CD16 labeling, cells were washed and permeabilized using FACS permeabilizing solution (Becton-Dickinson), and subsequently incubated with the appropriate PEconjugated anti-IL-6, anti-TNF $\alpha$ or isotype control antibody (Becton-Dickinson).

For each sample, data from 5,000 cells were collected and analyzed using a FACScalibur flow cytometer and CellQuest software (Becton-Dickinson). Forward and side scatters were used to gate monocytes and to exclude cellular debris. During analysis, an electronic gate was placed on $\mathrm{CD} 14^{++}{ }^{\text {(high) }} \mathrm{CD} 14^{+}{ }^{\text {(low) }}$-positive cells, and the associated expression of CD16 and TLR1 or TLR2 or cytokines was determined by multicolor analysis. The proportion of various subsets of monocytes $\left(\mathrm{CD} 14^{++(\text {high })}\right.$ $\mathrm{CD} 16^{-}, \mathrm{CD} 14^{++(\text {high) }} \mathrm{CD} 16^{+}, \mathrm{CD} 14^{+(\text {low })} \mathrm{CD} 16^{-}$, and $\mathrm{CD} 14^{+(\text {low) }} \mathrm{CD} 16^{+}$) expressing TLR1 and TLR2, or containing intracellular IL- 6 and TNF- $\alpha$, were analyzed for numbers and mean fluorescence channel number (MFC\#, indicator of the density of TLR receptors on cell surface)

\section{Activation of ERK Kinases}

To study TLR1/2-mediated signaling in monocyte subsets, whole peripheral blood was activated with $5 \mu \mathrm{g} / \mathrm{ml}$ of pam3ys for $10 \mathrm{~min}$. Activation of ERK was determined by intracellular phospho protein technique and flow cytometry using the protocol provided by the manufacturer of phophoflow kit (BD Biosciences). Briefly, cells were fixed immediately following activation with pam3Cys using BD Phosflow Lyse/Fix Buffer, permealized by adding $1 \mathrm{ml}$ of Phosflow Perm/Wash Buffer to $10^{7}$ cells, and incubated for $10 \mathrm{~min}$ at room temperature with the appropriate PEconjugated phopho ERK1/2-specific anti bodies and FITCconjugated anti-CD14 and Alexa 687-labeled anti-CD16 monoclonal antibodies. Cells were washed and acquired and analyzed as described above. Fold change was calculated by dividing the median fluorescence intensity (MFI) of the stimulated sample (MFI stim) by that of the unstimulated sample (MFI unstim).

Activation of ERK was also determined in purified monocytes by Western blotting. Peripheral blood monocytes from young and aged subjects were purified by using magnetic nanobeads (Stem cell Technologie, Vancouver, British Columbia, Canada). Monocytes were activated with $5 \mu \mathrm{g} / \mathrm{ml}$ of pam3Cys for $10 \mathrm{~min}$, and lysed with lysing buffer (Tris-HCl pH $7.420 \mathrm{mM}, \mathrm{NaCl} 150 \mathrm{mM}$, Triton X$1001.2 \%$, EGTA $1 \mathrm{mM}$, PMSF $1 \mathrm{mM}$, aprotinin $0.15 \mathrm{U} / \mathrm{ml}$, leupeptin $10 \mu \mathrm{g} / \mathrm{ml}, \mathrm{NaNO}_{3}$ ). Protein concentration was determined by using a protein assay kit (Bio-Rad). An equal amount of protein was subjected to sodium dodecyl sulfate-polyacrylamide gel electrophoresis and transblotted onto polyvinylidene difluoride membrane (Millipore). After blocking, phosphorylation of ERK was determined by incubating the blot with phospho specific ERK antibodies (Cell Signaling, Danvers, MA, USA) followed by incubation with an appropriate HRP-labeled secondary antibody. The specific protein was detected by enhanced chemiluminescence (ECL) (GE-Amersham, Piscataway, NJ, USA). The blots were analyzed using Un-Scan-It software to estimate the density of the bands in pixels. Actin protein served as an internal loading control. 
Statistical analysis was performed by ANOVA. A value of $\leq 0.5$ is considered significant.

\section{Results}

Four subsets of monocytes in healthy young and aged subjects Monocyte subsets were analyzed in whole blood samples with FITC-anti-CD14 and Alexa687-anti-CD16 monoclonal antibodies and isotype controls using FACSCalibur. Figure 1a shows a representative cytoflourograph for the analysis of four subsets of monocytes. The order of frequency

a
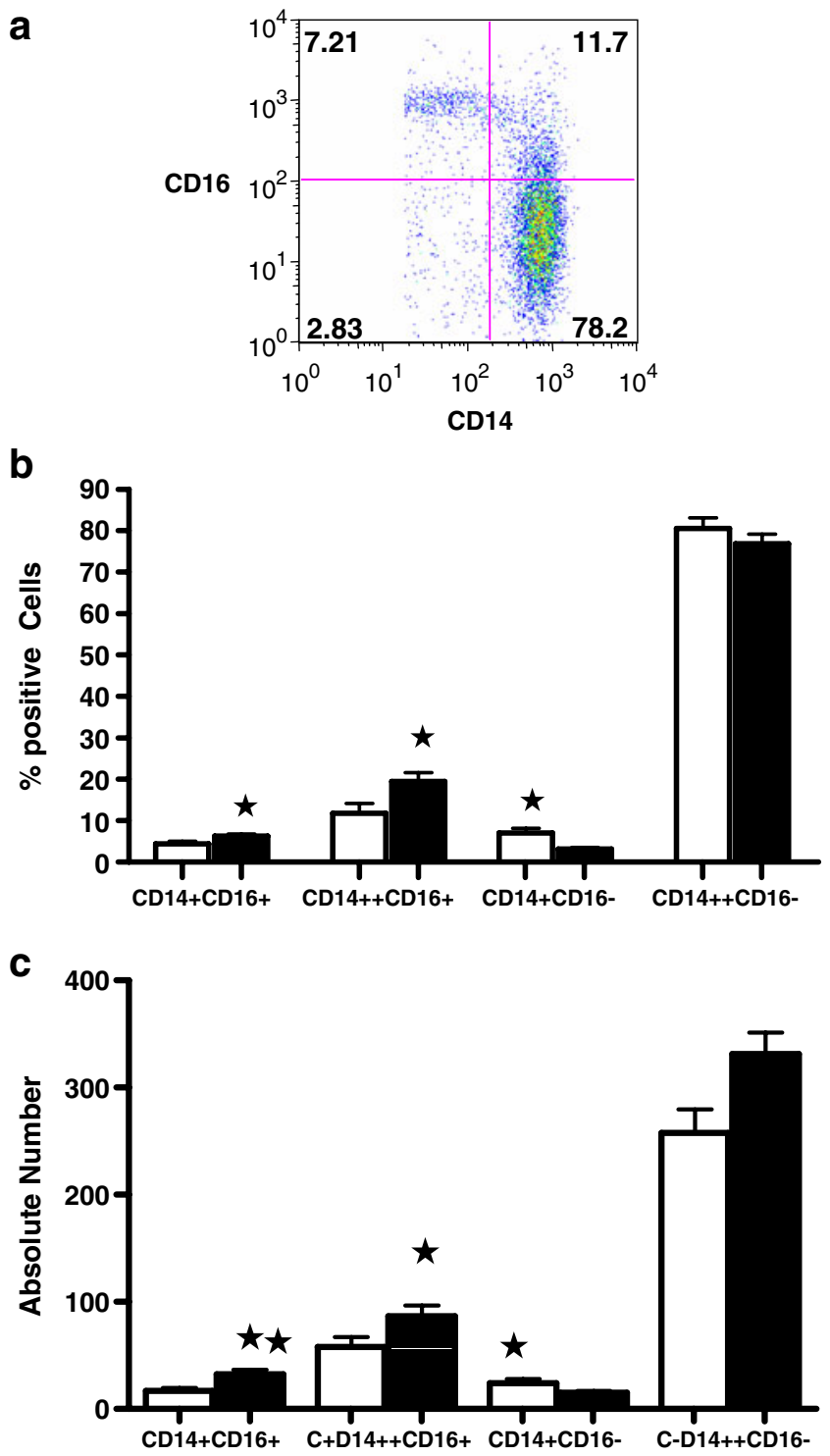

Fig. 1 Monocyte subsets in young and aged humans. a Representative cytofluorograph of four subsets of monocytes based upon expression of CD14 and CD16 antigens from a young subjects. b Cumulative data for the proportions and $\mathbf{c}$ numbers of four subsets of monocytes from 17 young and 17 aged subjects. Data are expressed as mean $\pm \mathrm{SD} . * P<0.05, * * P<0.01$ was $\mathrm{CD} 14^{++(\text {high) }} \mathrm{CD} 16^{-}$(major subset) $>\mathrm{CD} 14^{++(\text {high) }} \mathrm{CD} 16^{+}>$ $\mathrm{CD} 14^{+(\text {low })} \mathrm{CD} 16^{-}>\mathrm{CD} 14^{+ \text {(low) }} \mathrm{CD} 16^{+}$. Figures $1 \mathrm{~b}$ and $\mathrm{c}$ show the cumulative data for the proportions and absolute numbers, respectively, for all four subsets of monocytes from 17 young subjects and 17 aged subjects. A significant increase in the proportions $(<0.03)$ and number $(P<0.03)$ of $\mathrm{CD} 14^{++(\text {high })} \mathrm{CD} 16^{+}$, and $\mathrm{CD} 14^{+(\text {low })} \mathrm{CD} 16^{+}$monocytes, and a significant decrease in the proportions $(P<0.001)$ and numbers $(P<0.04)$ of $\mathrm{CD} 14^{+(\text {low })} \mathrm{CD} 16^{-}$was observed in aged subjects. No significant difference was observed between young and aged subjects in the proportions or numbers of $\mathrm{CD} 14^{++(\text {high })} \mathrm{CD} 16^{-}$subset.

TLR 1/2 agonist-induced cytokine production is reduced in aging Aging is associated with increased levels of circulating IL-6, and TNF- $\alpha$ [15], and since we observed increased numbers of monocyte subsets, we reasoned that monocyte subsets might be the major source of increased IL- 6 and TNF- $\alpha$ in aging. Therefore, we examined IL- 6 and TNF- $\alpha$ synthesis in all four subsets of monocytes following stimulation by pam3cys. Whole blood white blood cells were stimulated with pam3cys in the presence of brefeldin A to inhibit secretion of cytokines and intracellular TNF- $\alpha$, and IL-6 synthesizing cells were measured with multiple monoclonal antibodies defining monocyte subsets and antibodies against IL- 6 and TNF- $\alpha$ by multicolor flow cytometry using FACSCalibur. Figure 1a shows a representative cytofluorgraphs of IL- 6 and TNF- $\alpha$ producing subsets of monocytes in a healthy young subject. TNF- $\alpha$ production was significantly higher (Fig. 2b) in both subsets of $\mathrm{CD} 14^{+ \text {low }}$ monocytes $\left(\mathrm{CD} 14^{+} \mathrm{CD} 16^{+}\right.$and $\mathrm{CD} 14^{+} \mathrm{CD} 16^{-}$), as compared to two subsets of $\mathrm{CD} 14^{++}$high monocytes $\left(\mathrm{CD} 14^{++} \mathrm{CD} 16^{+}\right.$and $\left.\mathrm{CD} 14^{++} \mathrm{CD} 16^{-}\right)$in young subjects. This would be in agreement with reported increased TNF- $\alpha$ production by $\mathrm{CD} 14^{+} \mathrm{CD} 16^{+}$monocytes [13]; however, we did not observe any difference in IL-6 among four subsets of monocytes in young subjects (Fig. 2c). Furthermore, all four subpopulations of monocytes displayed significantly reduced $(P<0.01-P<0.05)$ IL6 production in aged (Fig. 2c) as compared to young subjects. However, the extent of decreased IL-6 production by $\mathrm{CD} 14^{+ \text {low }} \mathrm{CD} 16^{+}$and $\mathrm{CD} 14^{++} \mathrm{CD} 16^{+}$monocyte subset was significantly greater $(P<0.01)$ than decreased IL-6 production by two subsets of $\mathrm{CD} 16^{-}$monocytes $(P<0.05)$. TNF- $\alpha$ production was significantly decreased $(P<0.05)$ in all but $\mathrm{CD} 14^{+}$low $\mathrm{CD} 16^{+}$monocyte subsets in aged subjects as compared to controls (Fig. 2b). This would suggest a functional heterogeneity of two subpopulations of CD14 ${ }^{\text {+low }}$ monocytes.

TLR 1 expression is reduced in aged humans since pam3Cys stimulates both TLR 1 and TLR 2, we examined whether decreased cytokine production in monocyte subsets 
a
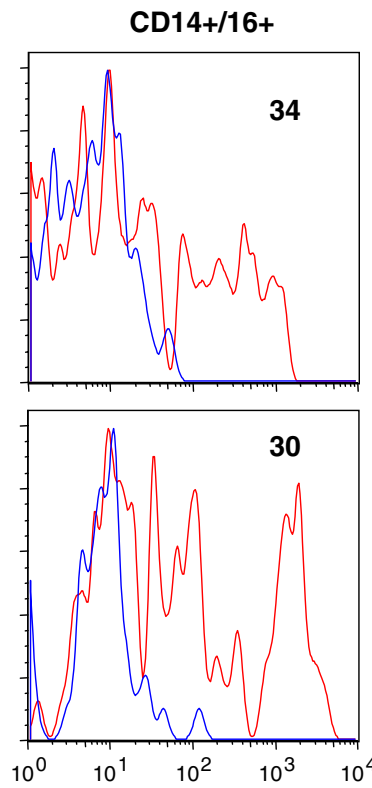

b

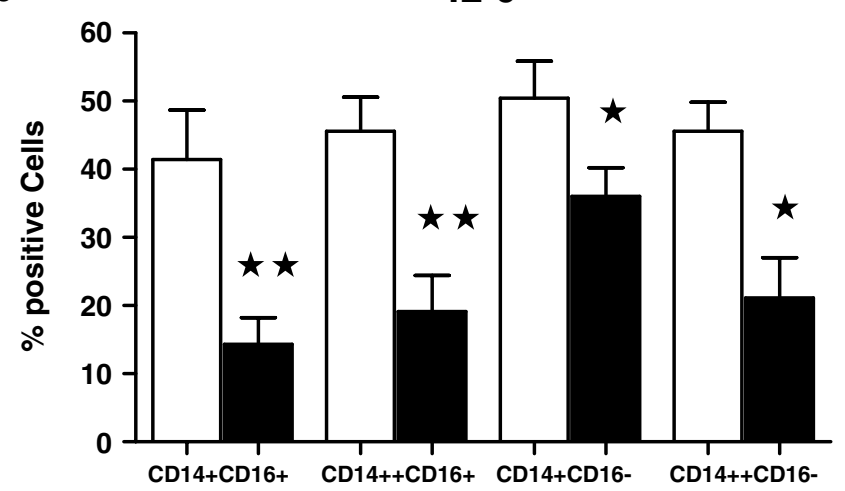

CD14+/16-
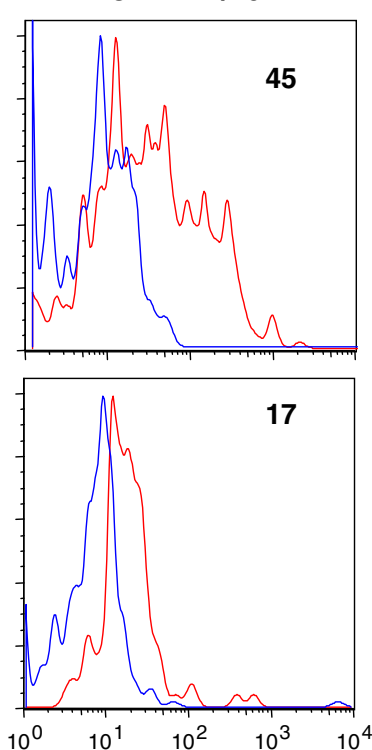
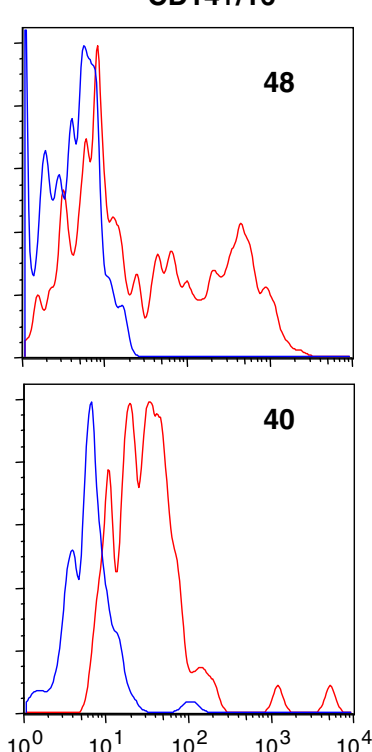

C
CD14++/16-

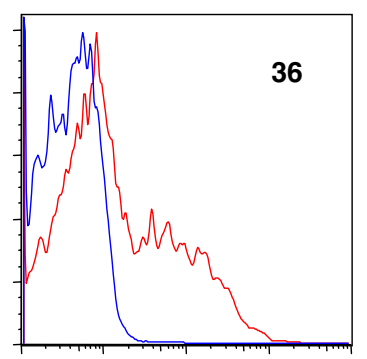

IL6

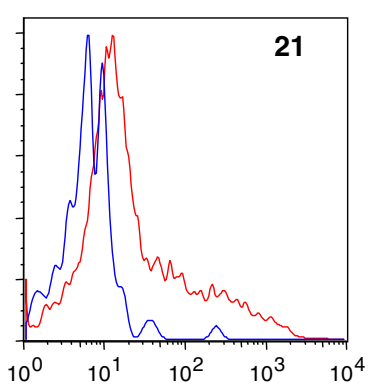

TNF $\alpha$

TNF $\alpha$

Fig. 2 Cytokine production by four subsets of monocytes in young and aged subjects. a Representative cytoflourograph of IL-6 and TNF- $\alpha$ production by four subsets of monocytes from young subjects. b Cumulative data for IL- 6 and $\mathbf{c}$ for TNF- $\alpha$ from young and aged subjects

is due to altered expression of TLR1 and/or TLR-2. No significant difference was observed in the proportions of four subsets of monocytes expressing TLR 2, or the density of TLR2 between young and aged subjects (data not shown). Figure 3 a shows a representative cytoflourograph of TLR1 expression in four subsets of monocytes in a young subject. A lower proportion of $\mathrm{CD} 14^{++}$high $\mathrm{CD} 16^{+}$ and $\mathrm{CD} 14^{+}$low $\mathrm{CD} 16^{+}$monocyte subsets expressed TLR1 as compared to $\mathrm{CD} 14^{+} \mathrm{CD} 16^{-}$and $\mathrm{CD} 14^{++} \mathrm{CD} 16^{-}$in young subjects. Figure $3 \mathrm{~b}$ shows cumulative data for the proportions of cell expressing TLR1, and Fig. 3c shows cumulative data of the density of TLR1 (as determined by mean fluorescence channel numbers (MFC\#)) in young and aged subjects. A significantly reduced expression of TLR 1 was observed in $\mathrm{CD} 14^{++}$high $\mathrm{CD} 16^{+}(P<0.03)$ and $\mathrm{CD} 14^{+}$low $\mathrm{CD} 16^{+}(P<0.007)$ from aged as compared to young subjects. Similarly, a significantly reduced density of TLR1 was observed in $\mathrm{CD} 14^{++}$high $\mathrm{CD} 16^{+}$and $\mathrm{CD} 14^{+}$low $\mathrm{CD} 16^{+}$ monocytes $(P<0.05)$. Therefore, it is likely that decreased cytokine production in aging is due to an impaired expression of TLR 1.

Phosphorylation of ERK1/2 is reduced in aged monocytes Protein was purified from isolated monocytes from young and aged subjects with or without stimulation with Pam3cys and analyzed by Western blotting using native and phosp ERK1/2 monoclonal antibodies, and quantified by densitometer. Figure 4a shows a representative Western blot gel and densitometry data. Monocytes from aged subjects displayed decreased phosphorylation of ERK1/2 as compared to young subjects. We then examined phosphorylation of ERK1/2 in all four subsets of monocytes from young and aged subjects with native and phopho ERK1/2 antibody and multicolor flow cytometry using FACSCalibur. 
a CD14+/16+

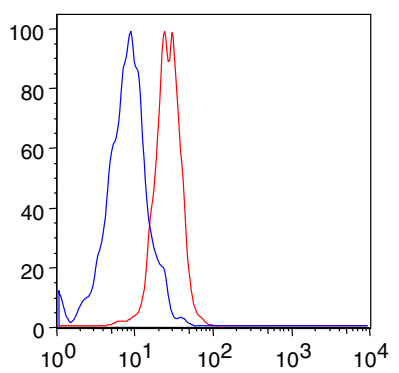

b

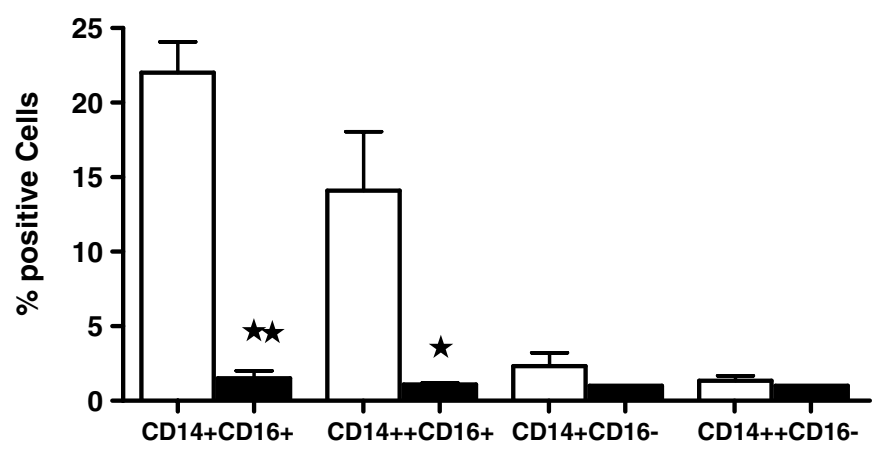

Fig. 3 Expression of TLR1 on four subsets of monocytes in young and aged subjects. Each subset of monocytes was gated, and proportions of each subset with TLR1 expression were expressed as percent of a particular subset of monocyte. a Representative

Figure $4 \mathrm{~b}$ shows a significantly decreased $(P<0.05-P<$ $0.005)$ phosphorylation of ERK1/2 in $\mathrm{CD} 14^{+(\text {low })} \mathrm{CD} 16^{+}$, $\mathrm{CD} 14^{+(\text {low })} \mathrm{CD} 16^{-}$, and $\mathrm{CD} 14^{++} \mathrm{CD} 16^{+}$subsets of monocytes from aged subjects as compared to young subjects. Furthermore, significantly greater reduction $(P<0.005)$ of ERK $1 / 2$ phosphorylation was observed in $\mathrm{CD} 14^{+(\text {low })} \mathrm{CD} 16^{-}$as compared to $\mathrm{CD} 14^{++(\text {high })} \mathrm{CD} 16^{+} \quad(P<0.02)$ and $\mathrm{CD} 14^{+(\text {low })} \mathrm{CD} 16^{+}(P<0.05)$.

\section{Discussion}

In this study, we have demonstrated alterations in the proportions and numbers, TLR1 expression, cytokine production, and phosphorylation of ERK1/2 in subsets of monocytes. These impairments in number and functions are more consistent in CD16+ monocytes and did not correlate with $\mathrm{CD} 14^{++ \text {high }}$ or $\mathrm{CD} 14^{+ \text {low }}$, the original subdivision of monocytes into two subsets. Therefore, this study highlights the need of further subdivision of monocytes in four subsets.

Aging is associated with the progressive decline in immune functions and increased susceptibility to microbial infections [1-3]. Although alterations in adaptive responses are well established, innate immune responses in human
CD14+/16-

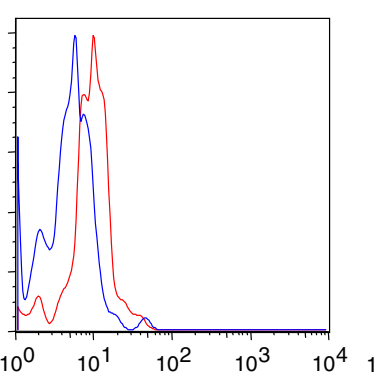

CD14++/16-
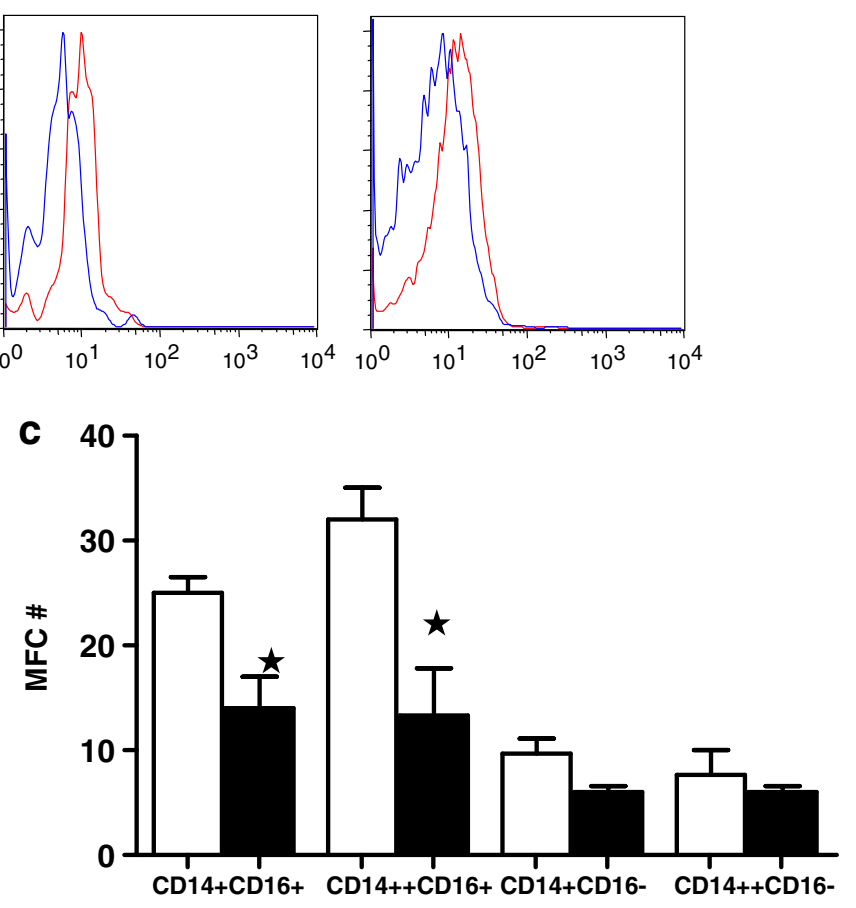

cytofluorograph from a young subject, b cumulative data for the proportions of TLR-1+ subsets, and $\mathbf{c}$ the fluoresecence intensity of TLR1 (mean fluorescence channel number (MFC\#)) of TLR-1 in each subset of monocytes from young and aged subjects

aging are not as well understood. TLRs are pathogen recognition receptors that recognize shared structural components from bacteria, fungi, and viruses [16-19]. Eleven TLRs in humans and 13 TLRs in mice have been described, and ligands for nine human TLRs are known. Monocytes/macrophages play an important role in defense against microbes and express several TLRs [19]. Initially, two subpopulations of monocytes were described in human monocytes-based expression of CD14 and CD16 molecules, their migratory properties, and cytokine production [6-12]. Kim et al. [20] described three subpopulations of monocytes in simian immunodeficiency virus infection. In humans, $\mathrm{CD} 14^{+(\text {low })} \mathrm{CD} 16^{+}$monocytes, by virtue of producing higher levels of proinflammatory cytokines (IL-6 and TNF- $\alpha$ ) as compared to $\mathrm{CD} 14^{\text {(high) }} \mathrm{CD} 16^{-}$monocytes, were termed proinflammatory monocytes. In this study, we analyzed four subpopulations of human monocytes, and we observed that two subpopulations of $\mathrm{CD} 14^{\text {(low) }}$ monocytes $\left(\mathrm{CD} 14^{+(\text {low })} \mathrm{CD} 16^{+}\right.$and $\left.\mathrm{CD} 14^{+(\text {low })} \mathrm{CD} 16^{-}\right)$contained increased levels of TNF- $\alpha$; however, we did not observe any significant difference for IL-6 among any of the four subsets of monocytes. A discrepancy for IL-6 between our results and those of others may be due to difference in the assays used. In our study, we analyzed intracellular cytokines (synthesized) in four subsets, whereas others have reported secreted cytokines in the culture supernatants 
a

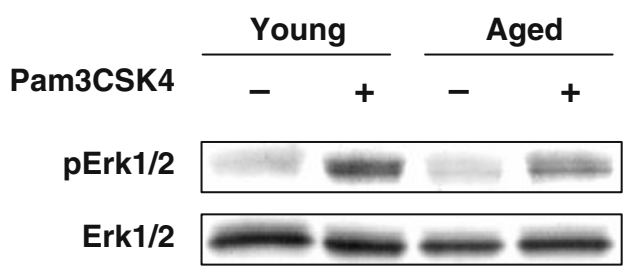

Total Erk1/2 normalized ratio

\begin{tabular}{|l|c|c|c|c|}
\hline & $\begin{array}{c}\text { Young } \\
\text { Control }\end{array}$ & $\begin{array}{c}\text { Young } \\
\text { Pam3CSK4 }\end{array}$ & $\begin{array}{c}\text { Aged } \\
\text { Control }\end{array}$ & $\begin{array}{c}\text { Aged } \\
\text { Pam3CSK4 }\end{array}$ \\
\hline pErk1/2 & 0.32 & 0.90 & 0.39 & 0.74 \\
\hline Erk1/2 & 1.00 & 1.00 & 1.00 & 1.00 \\
\hline
\end{tabular}

b PERK

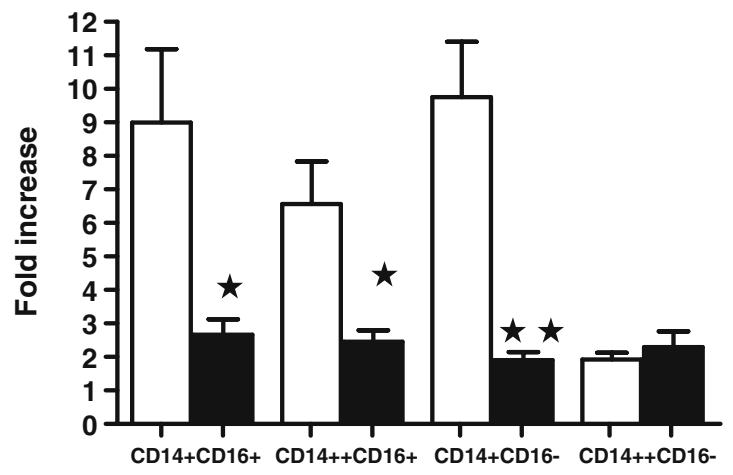

Fig. 4 Phosphorylation of ERK1/2 in monocyte subsets from young and aged subjects. a Representative Western blot of ERK1/2 phosphorylation and densitometric analysis following Pam3CSK4 stimulation of total monocytes from young and aged subjects. b Cumulative data of phosphor ERK1/2 in four subsets of monocytes by flow cytometry

of two purified subsets of monocytes [10, 12]. Similar discordant was observed for TNF- $\alpha$ using different methods of measurement of cytokines [13]. Belge et al. [13] observed no difference in TNF- $\alpha$ mRNA between CD14 ${ }^{++}$ $\mathrm{CD} 16^{-}$and $\mathrm{CD} 14^{+} \mathrm{CD} 16^{+}$monocytes (only two monocyte subpopulations were analyzed); however, using intracellular cytokine staining, they observed higher levels of TNF- $\alpha$ in $\mathrm{CD} 14^{+} \mathrm{CD} 16^{+}$subsets.

In the present study, we also analyzed four subsets of human monocytes and their functions in aged humans. Proportions and numbers of $\mathrm{CD} 14^{++(\text {high) }} \mathrm{CD} 16^{+}$and $\mathrm{CD} 14^{+(\text {low })} \mathrm{CD} 16^{+}$monocytes were increased in aged subjects, whereas proportions and numbers of $\mathrm{CD} 14^{+(\mathrm{low})} \mathrm{CD} 16^{+}$ monocytes were decreased in aged as compared to young subjects. There was no correlation between the changes in proportions and numbers of monocyte subsets and TLR1 expression, cytokine production, or ERK1/2 phophorylation (data not shown).

Aging is associated with increased levels of proinflammatory cytokines IL-6 and TNF- $\alpha$ [21, 22]. Since we observed an increased number of monocyte subsets in aging, we expected that monocytes may be a source of increased IL- 6 and TNF- $\alpha$ in aging. However, our data show that pam3Cys (a ligand for TLR1 and TLR2)-induced IL-6 and TNF- $\alpha$-producing cells were significantly reduced in aged monocyte subsets as compared to that of young subjects. This is in agreement with published data for total or two subsets of monocytes in aged subjects in response to TLR2 and TLR4 activation [23, 24]. Furthermore, subpopulations of $\mathrm{CD} 14^{+(\text {low })}$ monocytes $\left(\mathrm{CD} 14^{+(\text {low })} \mathrm{CD} 16^{-}\right)$ had significantly fewer changes for IL- 6 or no change in TNF- $\alpha$ production in aged as compared to other monocyte subsets. This observation highlights the importance of analyzing four subpopulations of monocytes. In mice, several investigators have reported decreased IL- 6 and TNF- $\alpha$ production by splenic and activated peritoneal macrophages from aged mice activated by the ligands of TLRs as compared to young mice [15]. However, no significant change was observed in the expression of TLR2 ad TLR4 in aged mice as compared to young mice. van Duin and colleagues [25] also reported reduced IL- 6 and TNF- $\alpha$ production by total monocyte population from aged humans following TLR1/2 stimulation. Our study may have an advantage and perhaps reflect more in vivo events, since experiments were performed in whole blood and gated subpopulations of monocytes rather than isolated monocytes, as in the study of van Duin et al. [25], which may result in a loss of a preferential subset of monocytes. In the present study, we have measured the number of various monocyte subsets producing cytokines in whole blood samples rather than cytokines produced in culture supernatants. Taken together, it appears that cells other than monocyte subsets are the source of increased levels of IL-6 and TNF- $\alpha$ in aged humans. Recently, we have reported that dendritic cells from aged subjects secrete increased amounts of proinflammatory cytokines, and may be the cell type contributing to the increased circulating levels of proinflammatory cytokines in aged subjects [26].

A decreased cytokine production by monocyte subsets may result from decreased expression of TLR1 and/or TLR2. In aging mice, Renshaw et al. [15] reported decreased expression of all TLRs mRNA as compared to younger mice. However, we have observed that the proportion of cells expressing TLR2, as well as the density of TLR2 in all four subsets of monocytes from aged subjects, was comparable to that of young subjects (data not shown). In contrast, a significantly decreased expression of TLR1 was observed on $\mathrm{CD} 14^{++(\text {high })} \mathrm{CD} 16^{+}$and $\mathrm{CD} 14^{+(\text {low })} \mathrm{CD} 16^{+}$monocyte subsets from aged subjects. Interestingly, expression of TLR1 and TLR2 on various subsets of monocytes from young subjects was different. TLR2 expression was significantly higher in $\mathrm{CD} 14^{++(\text {high })}$ $\mathrm{CD} 16^{+}$and $\mathrm{CD} 14^{+(\text {low })} \mathrm{CD} 16^{+}$as compared to $\mathrm{CD} 14^{++(\text {high })}$ 
CD $16^{-}$and $\mathrm{CD} 14^{+(\text {low })} \mathrm{CD} 16^{-}$monocytes (data not shown). In contrast,TLR1 expression was predominantly on $\mathrm{CD} 14^{++(\text {(high) }} \mathrm{CD} 16^{+}$and $\mathrm{CD} 14^{+(\text {low })} \mathrm{CD} 16^{+}$as compared to $\mathrm{CD} 14^{++(\text {high) }} \mathrm{CD} 16^{-}$and $\mathrm{CD} 14^{+(\text {low })} \mathrm{CD} 16^{-}$monocytes. No such study of TLR expression in various monocyte subsets has been reported. van Duin et al. [25] also reported normal TLR2 expression and decreased TLR1 expression in total monocyte population in aged humans.

TLR agonists induce proinflammatory cytokine secretion via activation of ERK-MAP kinase signaling pathway [2729]. Kopp et al. [29] demonstrated that the activation of adipocytes with pam3cys resulted in the secretion of IL-6, which was dependent upon phosphorylation of ERK. Agrawal et al. [27] reported that activation of DCs via TLR4 and TLR5 resulted in the phosphorylation of p38 and c-Jun N-terminal kinase 1/2 (JNK1/2), whereas activation of DCs via pam3cys (TLR2 ligand) resulted in a sustained phosphorylation of ERK1/2. Dillon and colleagues [28] reported that the activation of DCs by Zymosan, a stimulus for TLR2, resulted in the phosphorylation of ERK1/2. In both aged mice and aged humans, macrophages/monocytesdecreased basal levels of p38 MAPK have also been reported [23-25]. However, no study on ERK1/2 activation in aged monocytes has been reported. In this study, we observed that pam3Cys-induced phosphorylation of ERK1/ 2 was decreased in all subsets of monocytes in aging, suggesting that decreased IL- 6 and TNF- $\alpha$ synthesis in aged humans appears to be in part due to impaired TLR1/2 signaling mediated via ERK1/2 pathway. Since TLR1/2 is a heterodimer, which is stimulated by pan3cys, it remains to be determined whether the signaling defect is via TLR 1 or both TLR1 and TLR2. In the present study and those reported by van Duin et al. [25], TLR-2 expression is comparable between young and aged subjects; therefore, it is likely that the defect in monocyte subsets in aged humans lies in TLR1-mediated signaling. TLR1/2 senses pathogen recognition molecules shared by a range of pathogens including Mycobacterium tuberculosis, Borrelia burgdorferi. This may also explain increased susceptibility to a number of microbes during aging, as well as poor response to vaccination. This would be consistent with impaired response to OspA vaccine (OspA is a ligand for TLR1/2) against Lyme disease in the elderly, which was associated with TLR1 defect but preserved TLR2 response [30].

In summary, human aging is associated with alterations in the numbers of certain subpopulations of monocytes, and impaired secretion of IL- 6 and TNF- $\alpha$, which appear to be due to an impaired expression of TLR1 and signaling via ERK1/2 pathway. Furthermore, in aged subjects, greater and more significant changes were observed in CD16+ (independent of level of CD14 expression, CD14 $4^{++ \text {high }}$ or $\mathrm{CD} 14^{+ \text {low }}$ ) monocytes as compared to $\mathrm{CD} 16^{-}$monocyte subsets (regardless of levels of CD14 expression). Therefore, it is important to analyze monocytes into four subsets. These defects in monocytes may play a role in increased susceptibility to microbial pathogens and poor response to vaccines in aged humans.

Open Access This article is distributed under the terms of the Creative Commons Attribution Noncommercial License which permits any noncommercial use, distribution, and reproduction in any medium, provided the original author(s) and source are credited.

\section{References}

1. Linton P, Dorshkind K. Age-related changes in lymphocyte development and function. Nat Immunol. 2004;5:133-9.

2. Caruso C, Buffa S, Candore G, Colonna-Romano G, DunnWalters D, Kipling D, et al. Mechanisms of immunosenescence. Immun Ageing. 2009;22:6-10.

3. Castle SC. Clinical relevance of age-related immune dysfunction. Clin Infect Dis. 2000;31:578-85.

4. Serbina NV, Jia T, Hohl TM, Pamer EG. Monocyte-mediated defense against microbial pathogens. Ann Rev Immunol. 2008;26:421-52.

5. Ziegler-Heitbrock L. The CD14+CD16+ blood monocytes: their role in infection and inflammation. J Leukoc Biol. 2007;81:584-92.

6. Passlick B, Flieger D, Ziegler-Heitbrock HWL. Identification and characterization of a novel monocyte subpopulation in human peripheral blood. Blood. 1989;74:2527-34.

7. Auffray C, Fogg D, Garfa M, Elain G, Join-Lambert O, Kayal S, et al. Monitoring of blood vessels and tissues by a population of monocytes with patrolling behavior. Science. 2007;317:666-70.

8. Geissmann F, Jung S, Littman DR. Blood monocytes consist of two principal subsets with distinct migratory properties. Immunity. $2003 ; 19: 71-82$.

9. Grage-Griebenow E, Lorenzen D, Fetting R, Flad HD, Ernst M. Phenotypical and functional characterization of $\mathrm{Fc} \gamma$ receptor I (CD64)-negative monocytes, a minor human monocyte subpopulation with high accessory and antiviral activity. Eur J Immunol. 1993;23:3126-35.

10. Wang SV, Mak KL, Chen LY, Chou MP, Ho CK. Heterogeneity of human blood monocytes: two subpopulations with different size, phenotypes, and functions. Immunology. 1992;77:298-303.

11. Tacke F, Randolph GJ. Migratory fate and differentiation of blood monocyte subsets. Immunobiology. 2006;211:609-18.

12. Weber C, Belge KU, van Hundelshausen P, Draude G, Steppich B, Meck M, et al. Differential chemokine receptor expression and functions in human monocyte subpopulations. J Leukoc Biol. 2000;67:699-704.

13. Belge KU, Dayyani F, Horelt A, Siedler M, Frankenberger M, Frankenberger B, et al. The proinflammatory CD14+CD16+DR++ monocytes are a major source of TNF. J Immunol. 2002;168:3536-42.

14. Mizuno K, Toma T, Tsukiji H, Okamoto H, Yamazaki H, Ohta K, et al. Selective expression of CD16highCCR2- subpopulation of circulating monocytes with preferential production of haem oxygenase (HO)-1 in response to acute inflammation. Clin Exp Immunol. 2005;142:461-70.

15. Renshaw M, Rockwell J, Engleman C, Gewirtz A, Katz J, Sambhara S. Impaired Toll-like receptor expression and function in aging. J Immunol. 2002;169:4697-701.

16. Takeda K, Kaisho T, Akira S. Toll-like receptors. Ann Rev Immunol. 2002;21:335-76. 
17. Kawai T, Akira S. TLR signaling. Sem Immunol. 2007;19:24-32.

18. Iwasaki A, Medzhitov R. Toll-like receptor control of the adaptive immune responses. Nat Immunol. 2004;5:987-95.

19. Jenssens S, Beyaert R. Role of Toll-like receptors in pathogen recognition. Clin Microbiol. 2003;16:637-46.

20. Kim W-K, Sun Y, Do H, Autssier P, Halpern EF, Piatak M Jr., et al. Monocyte heterogeneity underlying phenotypic changes in monocytes according to SIV disease stage. J Leukoc Biol. 2010;87:557-67.

21. Bruunsgaard H, Pedersen BK. Age-related inflammatory cytokines and diseases. Immunol Allergy Clin North Am. 2003;23:15-39.

22. Krabbe KS, Pedersen BK, Bruunsgaard H. Inflammatory mediators in the elderly. Exp Gerontol. 2004;39:687-99.

23. Boehmer ED, Meehan MJ, Cutro BT, Kovacs EJ. Aging negatively skews macrophage TLR2- and TLR4-mediated proinflammatory responses without affecting the IL-2-stimulated pathway. Mech Ageing Dev. 2005;26:1305-13.

24. Boehmer ED, Goral J, Faunce DE, Kovacs EJ. Age-dependent decrease in Toll-like receptor 4-mediated proinflammatory cytokine production and mitogen-activated protein kinase expression. L Leukoc Biol. 2004;75:342-9.

25. Van Duin D, Subhasis M, Thomas V, Ginter S, Montogomery RR, Fikrig E, et al. Age-associated defect in human TLR-1/2 function. J Immunol. 2007;178:970-5.
26. Agarwal A, Agrawal S, Cao JN, Su H, Osann K, GUPTA S. Abberant innate functions of dendritic cells in aged humans: a role of PI3-K signaling pathway. J Immunol. 2007;178:691222.

27. Agrawal S, Agrawal A, Doughty B, Gerwitz A, Blenis J, Van Dyke $\mathrm{T}$, et al. Different toll-like receptor agonists instruct dendritic cells to induce distinct $\mathrm{Th}$ responses via differential modulation of extracellular signal-regulated kinase-mitogenactivated protein kinase and c-fos. J Immunol. 2003;171: 4984-9.

28. Dillon S, Agrawal S, Banerjee K, Letterio J, Denning TL, Oswald-Richter K, et al. Yeast zymosan, a stimulus for TLR-2 and dectin-1, induces regulatory antigen-presenting cells and immunological tolerance. J Clin Invest. 2006;116:916-28.

29. Kopp A, Buechlet C, Bala M, Neumeier M, Scholmerich J, Schaffler A. Toll-like receptor ligands cause proinflammatory and prodiabetic activation of adipocytes via phosphorylation of xetracellular signal-regulated kinase and c-Jin N-terminal kinase but not interferon regulatory factor-3. Endocrinology. 2010;15:1097-108.

30. Alexopoulou L, Thomas V, Schnare M, Lobet Y, Anguita J, Schoen RT, et al. Hyporesponsiveness to vaccination with Borrelia burgdorferi OspA in humans and in TLR-1 and TLR-2 deficient mice. Nat Med. 2002;8:878-84. 